\title{
Discussion on Agricultural Development Evolution and Value in the Narrowly Area of Western Yunnan
}

\author{
Zilin Zhou \\ Baoshan College, Yunnan, 678000, China
}

Keywords: Narrowly area of western Yunnan, Agricultural development, Evolution, Value.

\begin{abstract}
The narrowly area of western Yunnan is located in Nu River west border areas, from the Yuan Dynasty, the narrowly western Yunnan region (ancient called Yongchang or Yongchang Prefecture) experienced the sequence of agricultural development evolution of irrigated agriculture, mountain agriculture, dam agriculture, specialty agriculture plateau and modern agriculture. This evolution reflects the region people's superior intelligence of survival and development, for people to understand the history of agricultural development and the corresponding agricultural civilization in the region, as well as accelerate the development of agriculture in the narrowly area of western Yunnan has theoretical and practical value.
\end{abstract}

\section{Introduction}

The narrow sense of Western Yunnan region it refer to the region on t of Nujiang River, including only Baoshan City and Dehong Dai and Jingpo autonomous prefecture, the population and total area of these two places take $7.9 \%$ and $8.09 \%$ of Yunnan province. The narrow sense of Western Yunnan region geographically located southern part of Heng Duan Mountain, bordered with Burma, it the most convent and main passage from Yunnan to South and Southeast Asia countries; mountains and alpine valleys spread over the region, including the famous GaoLi Gong Mountains, Nu Jing river, Cang lanjiang river, Yiluo Wadi river, Binlang Jiang River, Longchuang Jian river, ect; the forest coverage in these two regions are Baoshan city 62\%, Dehong prefecture 67.1\%; the am district is not very big $^{[1]\left(\mathrm{p}^{11)}\right.}$; it is located in the tropical and subtropical monsoon climate, the climate is warm. The agricultural in this region has formed into its own strong characters due to the limitation of its unique historical, geographical, climatic and geographic conditions and other factors. It experienced five evolution stages along with time vicissitude in practical, each made its own unique theoretical value and practical value.

\section{The evolution stages of agricultural development in the narrow sense of western Yunnan region}

The agricultural development in the narrow sense of Western Yunnan region can be divided into five evolution stages along with time vicissitude.

\section{Irrigated agriculture}

Before Ming dentistry, the agriculture in narrow sense of western Yunnan region is very backward, no scientific historical records. From the periods of the Yuan Ming and Qing to early of 1980s, the agriculture in narrow sense of western Yunnan region focus on building water conversancy projects and managing water volume, it is traditional irrigated agriculture.

The period of Yuan, Ming and Qing three dynasties is a focusing period of developing and government to the Yongchang or Yongchuang Fu (current narrow sense of western Yunnan region); from the civil and military governors, prefecture chief in feudal China to county commissioner take water conservancy projects, water logging and drought relief, developing agriculture as top priority. [2]

Although the officers of YongchangFu in Ming Qing dynasties, consumed lots of silver from stocked and donation fund of country gentlemen and publics, and human labor and animal power, but they did constructed a numbers of water conservancy projects improved the number of fields 
moreover they development and implement a serious village rules like water allocation management system, and tree plantation and protection soil, etc, all these activities had dramatically interned local people' s living and production standard and promoted rapid and effective growth go local agriculture.

In the public China period, there rarely has any bright spot in the water conservancy projects, mainly stay on the remedial works in the narrow sense of western Yunnan region. After founding of new China, many water conversances were built in narrow sense of western Yunnan region, such as Baoshan Beimiao reservoir, Longling County Lameng Xiaolaingdi reservoir, Tengchong ContryJiannan team 15 km big ditch, Zhushan Changning 45 Tangba ,and Hetu river, Sankuai Shi reservoir, Xiangshui Ao reservoir, etc which greatly ensure the yield of the field. In 1980s during the Yang Shanzhou' s term as secretary of the prefectural party committee, Bao shancity start to enjoy the "waster Yunnan granary" of the name, ever since. Dehong prefecture, a no water conservancy before the liberation, it is separated from Baoshan since 1963, 1969 reunite, and 1971 formed separated as a prefecture, then it made rapid improvement of the construction of the water conservancies, like, many middle ranged reservoirs like LuxiCity MangJiu and Song He inn Yingjiang county, some small reservoir representative in Luxi Mneg bang richer and some "ice small featured conservancies projects, which effectively promoted the development of the local agricultural.

\section{Mountain area agriculture}

From the beginning of 1980s Yunnan province implemented the household contract responsibility system (commonly known as the fixing of farm output quotas for each household) by the end of the 1990s, the narrow sense of western of Yunnan with the good water conservancy facilities, development of rice and wheat planting is convenience and high yield, the agriculture should be called as mountain agriculture, since it intense to focused on to the mountain rejoin and benefit only by mass production.

During this period, benefit from the implementation of the household contract responsibility system with remuneration linked to output, greatly mobilize the activities of farmers in narrow sense of western Yunna region, guidance and the most representative's theory of agricultural development is: Professor Xu Jingjun proposed Yunnan must developing mountain area economy [4] p113-165, he emphasized that the transformation the middle and low yielding fields in the mountains, and developing animal husbandry and forestry; Xu Jing Jun Shi Jinshou proposed in mountainous area of Yunnan Province, the development of potato, corn, buckwheat and other upland crops in order to increase the grain yield of the ideas and countermeasures [5] p14-18. Meanwhile under the guidance of the theories, government officials in the narrow sense of western Yunnan region and farmers devoted themselves development of mountain area of grain, sugar, rape, coffee and animal husbandry, to meet people's satisfied demands and to rich agricultural resources. apart from grantee of grain production, Baoshan City in the 1980s also planted sugarcane in more than 60 million acres, and developed sugarcane as local pillar industry; for the livestock need of animals and the obstructed the road, Baoshan City, development of a large number of mountain sheep and cattle farming; in the 1990s, Baoshan City, vigorously developed mountain grain of corn, wheat, coffee, tea, tobacco, forest planting crops and economic crops. Among them, owing to rise in the price of coffee, the plantation of had increased to over to 10000 in 1999, Dehong Prefecture in the dam area to develop hybrid rice planting base, vigorously develop the mountainous wheat, corn, coffee, sugarcane, rapeseed, tobacco, watermelon planting and pig farming industries. Among them, it gained rapid development in coffee plantation in 90s.

\section{Agriculture in dam area}

Before the start of the new rural construction from 2000 to 2006, the narrow sense of western Yunnan region has many advantages in dam area and the favorite support for mountain agriculture, so it focused more to the development of agriculture in dam area, so called as agriculture in dam area

During this period, of the agriculture in the narrow sense of in western Yunnan regain is very low in efficiency, mountainous area agriculture, agriculture in mountainous areas are increasing 
flue-cured tobacco, coffee, corn and other crop planting, pig breeding cattle and sheep on top of 1990s,vigorously developed the cultivation of walnuts, coffee. while dam area agriculture has prominent advantages, mainly reflected in the following aspects: Baoshan City has 78 Bazi, 1560 square kilometers area, accounting for the city's 8\%, Dehong Prefecture has area of 20 large Bazi, 1728.9 square kilometers, accounting for the state of 15\%[1] (P11) in; Baoshan, Dehong Bazi is located in low altitude hot dam fertile land, irrigation facilities, suitable for planting crops variety, high yield; the population and labor in dam area is intensive, small agricultural credit more easy to obtain, convenient transportation, commercial prosperity, good market conditions and the accelerate urban construction and real estate development, demand rapid growth of agricultural products. These advantages have been clearly recognized and realized in practice. Baoshan City dam area to the rapid developed of yield and output value of agriculture, hybrid rice, tobacco, walnut, coffee, sugar cane, high-quality wheat, sericulture, potato, green beans (Vicia faba) and vegetables planting and pig breeding, become a big city in agricultural. Dehong dam area focused on the development of Gong rice, coffee, tobacco, sugarcane, wheat, corn, vegetables, watermelon and other growing and pig farming. Among them, in 2005 it achieved breakthrough results in sugarcane plantation for over 78 million acre

\section{Plateau Characteristic Agriculture}

Although Dehong Prefecture had in the 1990s in the 20th century put forward the concept of developing coffee to a plateau characteristic industry, but not until 2006 it officially started the plateau characteristic agriculture model with the development of new rural reconstruction in narrow sense of western Yunnan region

The development of new rural reconstruction, many agricultural industrialization projects has been implemented, greatly stimulated characteristic agriculture industry development of the narrow sense of western of Yunnan plateau region. Many theories and researches been conducted during this period about the development of highland characteristic agricultural and one of the representative is Qing Hong Meng Hong Xiang Luo, editor in chief of the Yunnan Plateau study on development of characteristic agriculture, have a pointed : Yunnan Plateau characteristic agriculture is rich and diverse, quality and safe, four characteristics of state environmental protection, four seasons fragrance to cultivate leading enterprises, lay the plateau characteristic brand, development of coffee, tea, sericulture, flowers, rubber, rice, wheat, cattle and sheep, fish, chicken, characteristic agriculture developing agriculture through science and technology,.. [6] p1-112 Corresponding to these theories, the plateau agriculture has developed significant effectiveness. characteristic agriculture for Baoshan city are: coffee, walnut, dendrobium, sericulture, "two cigarettes", potato, vegetable greenhouses, good quality hybrid rice, beer with barley, tea, mug bean, canola, safflower tea, strawberry, litchi, sugarcane, edible bacteria, paddy fish, BingMa cattle, Longling goat, only rape, tea, mulberry, vegetables, fruit, coffee during the "Twelfth Five Year Plan" planting area reached 272 acres, to "Baoshan Beaton Coffee Co., Ltd., Yunnan Longling economy wide Yellow Goats limited liability company as the representative of the province, have more than 140 municipal agricultural leading enterprises. Dehong characteristic agriculture are: high quality rice, coffee, tobacco, sugarcane, tea, walnut, wheat, lemon, Agave americana, rubber, sweet and crisp corn, potatoes, watermelon, meat (milk) Buffalo, only the "Eleventh Five Year" period, Dehong "coffee, Betula alnoides, bamboo, tea, walnut, lemon and other planting area of 3 million mu, after the Hougu coffee, Zhegang gongmi and mahogany furniture, 115 enterprises" [7] p114.

\section{Modern agriculture}

In 2012,the 18 national party congress proposed to promote modernization development of agricultural in China, motive the development of agriculture narrow sense of western Yunnan region to move in the direction of development, based on the its characteristic agriculture. at present it had achieved some good results in many areas such as the popularization of agricultural machinery, construction of agricultural park, agricultural cooperatives, leading agricultural production enterprises, Internet plus agriculture, combination of agricultural trade and production, it also improved the commodity rate of agricultural products and the quantity and quality supplied products, increased the income of the farmers. Currently the development trend of the agricultures in the 
narrow sense of western Yunnan region is ecological agriculture, order agriculture, sightseeing agriculture, suburban agriculture and agricultural network, digital agriculture, one village one product and stereo agriculture common development, it will achieve better programs.

\section{The value of the five agricultural development stages of The narrow sense of Western Yunnan region}

\section{Theoretical value on understanding of the development status in The narrow sense of Western Yunnan region}

From the historical process of agricultural development in the narrow sense of western Yunnan region are irrigation agriculture, mountainous area agriculture, dam area agriculture, plateau characteristic agriculture, and modern agriculture consists it is the combination of theory and historical evidence, not a summarize the history of agricultural development in the region, but also clarify the previous confusion on the theories of the regional agricultural development and wrong understanding people may have; it can correctly unified awareness and to play the role of theoretical guidance, has important theoretical value. Moreover, this fie stages can correspond to development stage of civilization, the irrigation agricultural correspond to ancient farming civilizations, a mountainous area agriculture correspond to liberation of agricultural productivity of subsistence agriculture civilization under the household contract responsibility system, dam and plateau characteristic agriculture respectively, the correspond to the industrialization beginning and middle stage of seeking rich agricultural civilization, the modern agriculture correspond to the stage of industrialization of the developed agricultural civilization. Through understanding stage of agricultural development can understanding the development stage of civilization, has a theory oriented value.

\section{Reflected excellent survival and development wisdom of people in The narrow sense of Western Yunnan region}

Development of irrigation agriculture and construction of water consumptions in the narrow sense of western Yunnan regional reflects the hard course of survival, in period with frequent drought and flood disasters, extremely low agricultural productivity on the weather condition, which also is the only choices; mountain agriculture is a reflection of the household contract responsibility system and the implementation of the agricultural potential is temporarily unable to further play under the situation that people need food and rich agricultural supplies, they produced the conscious action of the array through personal hard work respectively developed the agriculture in the mountainous area; the dam area agriculture reflects the utilization of superior agricultural resources advantage in the early stage of industrialization, is the government's agricultural income tax anticipation and the people aspiring reflection; plateau characteristics agriculture reflects the middle stage of industrialization of agriculture principles that band characters have to develop bigger and stronger for long-term strategic choice; modern agriculture reflects the policy the implementation of the central committee of the CPC Central committee for the development of modern agriculture and the strategically planning for the future development of the regional agricultures.

\section{The reference value to the accelerate the development of agriculture in western Yunnan region}

Agricultural natural resources in the narrow sense of in western Yunnan region is very similar with the generalized sense of western Yunnan region (in addition to the Baoshan, Dehong also includes "Nujiang, Dali, Lijiang, Diqing Prefecture, Lincang, and Xishuangbanna Pu'er City,") such as hydropower, rich in forest resources and three-dimensional climate, they both are yield of natural resources in Yunnan Province, so the agricultural development experience of the narrow sense of western Yunnan region has reference value to the generalized sense of western Yunnan region. The first of all, abundant and clean water resources is essential to the development of agriculture, the region must further strengthen the construction of water conservancy resources, strict control of pollution, and solve the contradiction between industrial and agricultural ; secondly, dam and mountainous areas have their own advantages, cannot be neglected; thirdly, development of science 
and technology is need to the development of ecological environmental protection, safety and high quality, rich variety, seasons fragrance the brand of Plateau Characteristic Agriculture, and to cultivate of leading enterprises in improve the processing of agricultural and sideline products and additional value; finally, the development of modern agriculture has pointed out the direction of the development of entire western region of the agricultural industry, although not to immediately change cannot be achieved, but can be added on top of continuing development of the plateau characteristics agriculture, accelerating the development of ecological agriculture, order agriculture, sightseeing agriculture, suburban agriculture and agricultural Internet plus The agricultural industry, to achieve a qualitative leap and a better future.

\section{Conclusion}

With the development of economic and social in narrow sense of western Yunnan region, the regional agricultural experienced development correspond from low to high, named as irrigation agriculture, mountain agriculture, dam area agriculture, plateau characteristic agriculture to modern agriculture. Research and study development and evolution of the agricultural in the narrow sense of western Yunnan region have the important value, it can help us build a deep understanding of excellent wisdom in the survival and development of local people, a good history knowledge of the development of agriculture corresponding to social civilization, but also provide theory instruction to the accelerating the development of Plateau Characteristic ecological agriculture and modern agriculture development, and its mentors role in the development of entire western Yunnan region; it will increase the income of farmers in western Yunnan region and comprehensive realization of the well-off society.

\section{Acknowledgments}

This paper is a scientific research fund project of Yunnan Provincial Department of education in 2015, the project number: $2015 Y 479$.

\section{References}

[1] Su country. It opened the gate of Yunnan basin, Kunming economic secret: Yunnan people's publishing house, 2006

[2] dragon cloud major, edited by Zhou Zhongyue Li Chunlong. The new school seal, seal annals of Yunnan, Kunming: Yunnan people's publishing house, 2007

[3] Wu Chenhui. On the construction of irrigation and water conservancy in Nu River basin during the Ming and Qing Dynasties, Agricultural Archaeology, 2014 (6).

[4] Xu Jingjun. Yunnan mountain economy, Kunming: Yunnan people's publishing house, 1983

[5] Xu Jingjun, Shi Jinshou. Yunnan food problem is an important thinking and Countermeasure of, Journal of Yunnan Institute of nationalities, 1991 (3).

[6] Meng Qinghong, Luo Hongxiang. Research on the characteristics of agriculture development in Yunnan plateau , Kunming: Yunnan people's publishing house, 2014

[7] Feng Zixun, Wang he. Reflections on the development of agricultural industry in Dehong, The ideological front, 2013 (39). 